\title{
An Alternative Method of Isolating the Membrane of a Halophilic Bacterium
}

\author{
By A. D. BROWN, C. D. SHOREY AND H. P. TURNER \\ Department of Microbiology, University of New South Wales, Sydney, and. \\ the Electron Microscope Unit, University of Sydney, Sydney, Australia
}

(Received 21 May 1965)

\begin{abstract}
SUMMARY
The membrane of Halobacterium halobium was isolated after rupturing the organisms osmotically in $0.02 \mathrm{M}-\mathrm{MgCl}_{2}$. Selected properties of this membrane were compared with those of membranes isolated from organisms which had been ruptured mechanically in $5 \mathrm{M}-\mathrm{NaCl}$. The two types of preparation were indistinguishable from one another in the electron microscope, but some differences were noted between the present series of preparations and those described earlier. These differences, of which the occasional retention of the characteristic surface pattern of this organism was notable, were attributed to a slight modification of fixation conditions used in the present work. There were no major chemical differences between the two types of preparation but some minor differences in $\mathbf{H}^{+}$titration and carbohydrate analyses possibly reflected slight structural differences between the two types of preparation. The osmotic method described here is much quicker than the mechanical one and, unlike the mechanical one, the time involved is largely independent of the quantity of organisms being used.
\end{abstract}

\section{INTRODUCTION}

The properties of a complex subcellular component isolated from a living organism are presumably dependent to some extent on the isolation procedure used. Lipoprotein membranes are not likely to be an exception to this generalization (see for example Ponder, 1961) and it is a reasonable assumption that an isolated membrane differs in various ways from the functional structure in a viable organism. The opportunities for isolating a microbial membrane by more than one method, however, are limited. Membranes from Gram-positive bacteria and structurally related organisms are normally obtained by digesting the cell wall enzymically (with risk of changes in the membrane) followed by osmotic rupture of the protoplast. At the present time there is apparently no alternative to this. The two membranous components of the envelope of most Gram-negative bacteria are not easy to separate from each other but together they can be separated from the rest of the cell by ultrasonic treatment or by any of several fundamentally similar mechanical methods of rupturing the organism. The extremely halophilic bacterium Halobacterium halobium is bounded by a single lipoprotein membrane (Brown \& Shorey, 1963) which hitherto has been isolated only by mechanical breakage of the organisms in the presence of high concentrations of $\mathrm{NaCl}$ followed by centrifugation in salt solutions. Because these organisms grow in high concentrations of $\mathrm{NaCl}$ they can be subjected, by dilution of their suspending medium, to a very large 
osmotic shock. Such a simple dilution procedure cannot be used for isolating the membrane, however, because the membrane itself dissolves at decreased salt concentrations (Brown, 1964). Membrane dissolution is caused by electrostatically induced disaggregation of the structure and can be prevented by high concentrations of monovalent cations or relatively low concentrations of bivalent cations (Brown, 1964). Concentrations of bivalent cations which are sufficient to stabilize the membrane against electrostatic dissolution are insufficient to stabilize the organism against osmotic rupture. This fact has been used to provide an alternative method which is quicker than mechanical breakage of the organisms, and which can be used on a larger scale than the mechanical or ultrasonic techniques so far available to the authors. Slight differences in the properties of membranes isolated by osmotic lysis on the one hand, and mechanical disintegration on the other, are relevant to an ultimate understanding of membrane structure.

\section{METHODS}

Organism. Halobacterium halobium was grown for 3 days at $30^{\circ}$ with rotary agitation. The growth medium contained Oxoid peptone $(1 \%, w / v)$ in the salts solution described by Sehgal \& Gibbons (1960).

Isolation of cell membrane. The culture was centrifuged at $2600 \mathrm{~g}$ for $20 \mathrm{~min}$. The deposit was divided into two parts and each half treated separately as follows. (i) One half was suspended in $5 \mathrm{M}-\mathrm{NaCl}$ at $4^{\circ}$ and portions of this suspension were shaken with glass beads in a Mickle tissue disintegrator for $30 \mathrm{~min}$. in an ambient temperature of $4^{\circ}$, with intermittent cooling in an ice bath (Brown, 1961). For this purpose the organisms from $1.5 \mathrm{l}$. of culture were suspended in $80 \mathrm{ml} .5 \mathrm{M}-\mathrm{NaCl}$, and $20 \mathrm{ml}$. portions were shaken at a time. The time involved in this disintegration step, or with any other batch-type mechanical device, is proportional to the volume of suspension being processed. After $30 \mathrm{~min}$. the beads were removed on a coarse sintered-glass filter. The membrane suspension was centrifuged for $1 \mathrm{hr}$ at 14,000$17,000 \mathrm{~g}$ and thereafter purified by a series of fast and slow depositions in a centrifuge (Brown, 1961). Throughout the whole procedure the membranes were suspended in cold $5 \mathrm{M}-\mathrm{NaCl}$. (ii) The second half of the centrifuged deposit was suspended, with rapid mixing, in $0.02 \mathrm{M}-\mathrm{MgCl}_{2}$ at $4^{\circ}$. For this purpose the organisms from 1.5 l. of culture were suspended in $80-100 \mathrm{ml}$. 0.02 $\mathrm{M}-\mathrm{MgCl}_{2}$. The organisms lysed virtually instantaneously and the suspension became unmanageably viscous with the release of deoxyribonucleic acid. The suspension was incubated at room temperature with sufficient deoxyribonuclease (DNase, about $2 \mathrm{mg}$. in $250 \mathrm{ml}$.) to decrease the viscosity effectively within $20 \mathrm{~min}$. The time lapse between suspending the organisms in $\mathrm{MgCl}_{2}$ solution and completing incubation with DNase was normally about $30 \mathrm{~min}$. and was largely independent of the mass of organisms (or volume of bacterial suspension). The suspension was then centrifuged at 14,000$17,000 \mathrm{~g}$ for $1 \mathrm{hr}$ and resuspended in cold $5 \mathrm{M}-\mathrm{NaCl}$. Sometimes it was found at this stage that not all the bacteria were broken, in which case the suspension in $5 \mathrm{M}-\mathrm{NaCl}$ was centrifuged and the deposit again suspended in $0.02 \mathrm{M}-\mathrm{MgCl}_{2}$ followed by incubation with DNase as before. After this second treatment virtually all the organisms had lysed. The extent of breakage on the first dilution was affected by the speed of mixing and by the volume of suspending solution. When the osmotically lysed bacteria were 
eventually resuspended in cold $5 \mathrm{M}-\mathrm{NaCl}$ they were fractionated in a centrifuge under conditions identical with those used for the mechanically broken half of the preparation. In both cases depositions in a centrifuge were continued until the appearances of the supernatant fluid and of the membrane suspension (the latter in a phase-contrast microscope) were consistent with adequate freedom from cytoplasmic contamination. This was usually achieved in 3-4 cycles of fast and slow depositions.

Electron microscopy. The techniques used were described fully by Brown \& Shorey (1963). Membrane preparations were fixed with buffered $\mathrm{KMnO}_{4}$ followed by uranyl nitrate as described except that in the present work the membranes were suspended in $5 \mathrm{M}-\mathrm{NaCl}$ instead of 'half-strength salts' up to the time of fixation. Fixed membranes were washed three times in water, deposited from aqueous suspension on to carbon-coated nitrocellulose supporting film and shadowed with gold-palladium or else they were embedded and sectioned. For the latter purpose they were dehydrated conventionally with ethanol, passed once through xylene, embedded in Araldite and sectioned (Brown \& Shorey, 1963). Both shadowed and sectioned specimens were examined in a Philips E.M. 200 electron microscope.

Chemical examination. Membrane suspensions were titrated at constant ionic strength in $4 \mathrm{M}-\mathrm{NaCl}$ with $0.02 \mathrm{~N}-\mathrm{NaOH}$ and $\mathrm{HCl}$. Details and implications of this technique, as applied to membranes, are discussed more fully elsewhere (Brown, 1965). In the present work, reference solutions of lipoprotein were not used since the aim of the titrations was merely to compare the two types of membrane preparation. After titration, membrane suspensions were dialysed exhaustively against distilled water at $4^{\circ}$ and the resulting lipoprotein solutions (Brown, 1964) were freeze-dried and weighed. Protein (Lowry, Rosenbrough, Farr \& Randall, 1951), total phosphorus following digestion with $\mathrm{H}_{2} \mathrm{SO}_{4}$ and $\mathrm{HNO}_{3}$ (Fiske \& Subbarow, 1925), amino sugar (Rondle \& Morgan, 1955) and total hexose (Dische, 1955) were estimated in these preparations. The last two estimations were made on acid-hydrolysed ( $2 \mathrm{~N}-\mathrm{HCl}$ for $2 \mathrm{hr}$ at $100^{\circ}$ ) lipoprotein.

\section{RESULTS AND DISCUSSION}

Electron microscopy. Shadowed membranes looked similar after both methods of isolation (Pl. 1, figs. 1-3) and, with one important exception, the same as encountered previously by Brown \& Shorey (1963). The exception was that a few individual membranes retained the surface pattern noted by Houwink (1956) on whole organisms of this bacterium and subsequently by Kushner et al. (1964) on unfixed membranes isolated from Halobacterium cutirubrum. This pattern was not encountered previously by Brown \& Shorey (1963) in membranes suspended in 'halfstrength salts' up to the time of fixation; it is likely that the use of $5 \mathrm{~m}-\mathrm{NaCl}$ in the present work assisted in preserving the surface structure. The pattern was encountered more frequently in membranes isolated by mechanical breakage of the organisms than by osmotic lysis but not enough preparations were examined to allow any statistical evaluation of this statement.

When examined in thin section there was no apparent difference between membranes isolated by either method (Pl. 1, fig. 4; Pl. 2, figs. 1, 2) or, with an occasional exception, between the current series of isolates and those described by Brown \& 
Shorey (1963). The occasional exception was found in parts of membranes which resembled compound rather than unit membranes (Pl. 2, fig. 2). This kind of appearance was encountered previously by Brown \& Shorey (1963) in sections of whole organisms of Halobacterium halobium but was not seen in isolated membranes. Like the surface pattern, the compound membrane appearance in isolated membranes was probably a result of the different ionic conditions during isolation. The compound appearance was encountered after both methods of isolation.

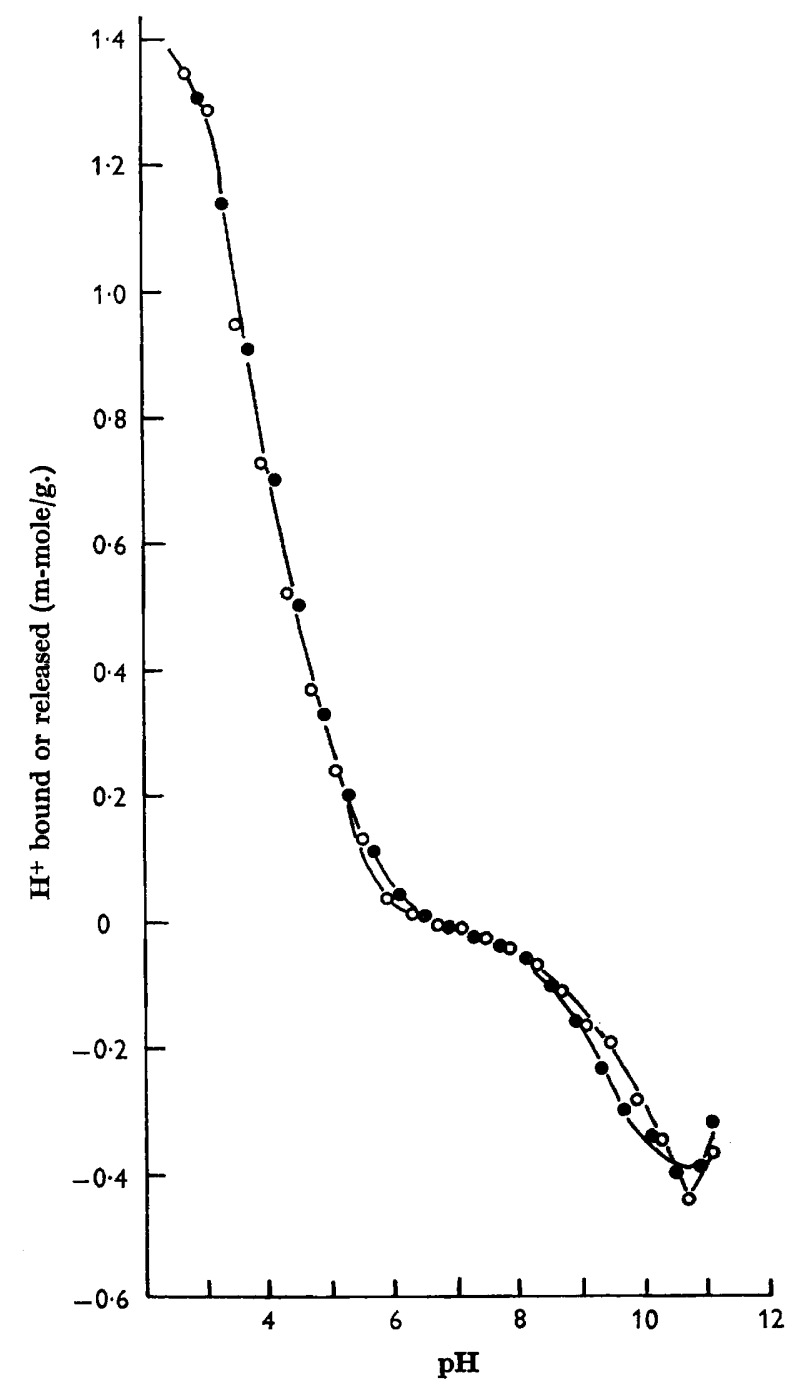

Fig. 1. Hydrogen-ion titrations of membranes (preparation 2) prepared by mechanical disintegration $\left(\mathrm{O}-\mathrm{O}\right.$ ) and osmotic lysis of organisms in the presence of $\mathrm{MgCl}_{2}$ $(\mathbf{0} \longrightarrow$ ).

\section{Hydrogen-ion titrations}

Titration curves of membranes isolated from the same culture by both methods are shown in Fig. 1. Many of the basic groups present on the lipoproteins of this organism do not titrate in the intact membrane and are presumed to be 'buried' 
in the deeper parts of the structure; $\alpha-\mathrm{NH}_{2}$ groups become titratable when the membrane swells, even slightly, in an ion deficit (Brown, 1965). This method of analysis is thus quite a sensitive one for detecting some subtle changes in membrane structure. The numbers of groups titrating in three pairs of preparations are shown in Table 1; from this it is apparent that $\mathrm{pH} 6 \cdot 0-8 \cdot 2$ was the only titration range in which there was a consistent difference between the two types of preparation, the osmotically lysed preparation having the higher titre. Groups titrating in this range include imidazole (of histidine), phosphate ( $\mathrm{pK}_{2}$ if phosphate mono-esters are present) and $\alpha-\mathrm{NH}_{2}$. The fact that $\mathrm{pH} \mathrm{6.0-8.2} \mathrm{was} \mathrm{the} \mathrm{only} \mathrm{range} \mathrm{in} \mathrm{which}$ differences between the two types of preparation were consistently obtained is in accord with the previous finding (Brown, 1965) that the bonds responsible for 'burying' $\alpha-\mathrm{NH}_{2}$ groups in this membrane are weak and easily disrupted. For reasons apparent from a fuller treatment of this topic (Brown, 1965) it is thought that in the present series of preparations the differences in titre were caused by the exposure of groups which were previously 'buried' rather than the converse. It is possible that a higher concentration of $\mathrm{MgCl}_{2}$ at the time of lysis would have prevented these slight differences in titre from arising but this was not investigated. In preliminary observations it was noted that an increase of $\mathrm{MgCl}_{2}$ concentration to $\mathbf{0 . 0 2 5} \mathrm{M}$ was accompanied by the rupture of noticeably fewer organisms.

\section{Table 1. Hydrogen-ion titrations}

Numbers of groups titrating in $4 \mathrm{~m}-\mathrm{NaCl}$ on three preparations of membranes isolated by both methods.

\begin{tabular}{|c|c|c|c|c|}
\hline \multirow[b]{2}{*}{ pH range } & \multirow{2}{*}{$\begin{array}{l}\text { Groups titrating } \\
\text { (theoret. pK) }\end{array}$} & \multirow[b]{2}{*}{ Preparation } & \multicolumn{2}{|c|}{$\begin{array}{c}\mathbf{H}^{+} \text {bound or released } \\
\text { (m-mole/g. membrane) }\end{array}$} \\
\hline & & & Mechanical & Osmotic \\
\hline $2 \cdot 8-6 \cdot 0$ & $\begin{array}{l}\alpha \text {-COOH (3.6) } \\
\beta \text {-and } \gamma \text {-COOH }(4 \cdot 6) \\
\text { Imidazole }(6 \cdot 2)\end{array}$ & $\begin{array}{l}\mathbf{1} \\
\mathbf{2} \\
\mathbf{3}\end{array}$ & $\begin{array}{l}1 \cdot 21 \\
1 \cdot 27 \\
1 \cdot 24\end{array}$ & $\begin{array}{l}1 \cdot 36 \\
1 \cdot 30 \\
1 \cdot 19\end{array}$ \\
\hline $6 \cdot 0-8 \cdot 2$ & $\begin{array}{l}\text { Imidazole }(6 \cdot 2) \\
\text { Phosphate }\left(\mathrm{pK}_{2}, 6 \cdot 5\right) \\
\alpha-\mathrm{NH}_{2}(c .7 \cdot 5)\end{array}$ & $\begin{array}{l}\mathbf{1} \\
\mathbf{2} \\
\mathbf{3}\end{array}$ & $\begin{array}{l}0 \cdot 07 \\
0 \cdot 09 \\
0 \cdot 13\end{array}$ & $\begin{array}{l}0 \cdot 15 \\
0 \cdot 12 \\
0 \cdot 15\end{array}$ \\
\hline $8.2-10.0$ & $\begin{array}{l}\alpha-\mathrm{NH}_{2}(c .7 \cdot 5) \\
\mathrm{Tyrosine}^{-\mathrm{OH}}(9 \cdot 5-9 \cdot 8) \\
\epsilon-\mathrm{NH}_{2}(10 \cdot 4)\end{array}$ & $\begin{array}{l}\mathbf{1} \\
\mathbf{2} \\
\mathbf{3}\end{array}$ & $\begin{array}{l}0.16 \\
0.24 \\
0.20\end{array}$ & $\begin{array}{l}0 \cdot 12 \\
0 \cdot 27 \\
0 \cdot 18\end{array}$ \\
\hline $10 \cdot 0-11 \cdot 0$ & $\begin{array}{l}\text { Tyrosine-OH }(9 \cdot 5-9 \cdot 8) \\
\epsilon-\mathrm{NH}_{2}(10 \cdot 4)\end{array}$ & $\begin{array}{l}1 \\
2 \\
3\end{array}$ & $\begin{array}{c}* \\
* \\
0.22\end{array}$ & $\begin{array}{c}* \\
* \\
0 \cdot 24\end{array}$ \\
\hline
\end{tabular}

* Titration had an alkaline end-point below pH 11.0.

The reasons for selecting these ranges of $\mathrm{pH}$ in which to compare titres are discussed elsewhere (Brown, 1965).

\section{Chemical analyses}

Table 2 summarizes results of chemical analyses of four classes of substance frequently used to characterize biological membranes and related structures. In one preparation lipoprotein from mechanically isolated membrane contained more phosphorus and the same amount or slightly less protein than its osmotically isolated counterpart; in the other preparations the converse was true. Thus variations in the proportion of phosphorus and protein cannot be attributed to the methods used for rupturing the organisms. Consistent differences were obtained, 
however, in the two sets of carbohydrate analyses; both amino sugar and total hexose were consistently higher in the lipoproteins isolated from mechanically ruptured organisms. It is not yet known whether these carbohydrates are part of polysaccharide present in small amounts in the membrane or of glycoprotein. Probably the amino sugar and hexose originated at least partly in different polymers, since different proportions of each were 'lost' on osmotic lysis. In two of three preparations the osmotically isolated lipoprotein contained about $40 \%$ less hexosamine and about $30 \%$ less hexose than did lipoprotein from mechanically ruptured organisms; the differences were less in the third preparation. For a component to differ by as much as $\mathbf{4 0} \%$ between preparations without reflecting the difference in other analyses, it must either be present in very small amounts or, alternatively, it must contain the other components analysed, namely phosphorus and protein, in the same proportion as the whole membrane; such a compound would be a lipoglycoprotein. Variations in the proportions of the components which contained the carbohydrates were not reflected in the electron microscopy of the membranes, but were correlated with differences in $\mathbf{H}^{+}$titre in the range $\mathrm{pH} \mathbf{6 \cdot 0 - 8 \cdot 2}$. It is not known whether there is any direct causal relationship between these two analytical differences but preparation 3, which had the smallest difference in carbohydrate analyses, also had the smallest difference in titre $(\mathrm{pH} 6 \cdot 0-8 \cdot 2)$ between the two types of preparation.

Table 2. The content (\%) of various substances in lipoprotein from membranes isolated by the two methods

$\begin{array}{lcccc}\text { Preparation } & \text { Phosphorus } & \text { Protein } & \begin{array}{c}\text { Amino sugar } \\ \text { (as glucosamine) }\end{array} & \begin{array}{c}\text { Hexose } \\ \text { (as glucose) }\end{array} \\ \text { 1. Mechanical } & 1.17 * & 76 & 1.03 & \mathbf{3 . 2 8} \\ \text { Osmotic } & 0.68 & 79 & 0.60(58 \%) \dagger & 2.82(71 \%) \\ \text { 2. Mechanical } & 1.02 & 75 & 0.87 & \mathbf{2 . 5 0} \\ \text { Osmotic } & 1.22 & 73 & 0.50(58 \%) & \mathbf{1 . 7 3}(69 \%) \\ \text { 3. Mechanical } & \mathbf{0 . 6 1} & \mathbf{7 7} & \mathbf{0 . 8 4} & \mathbf{2 . 4 2} \\ \text { Osmotic } & \mathbf{0 . 7 4} & \mathbf{7 3} & \mathbf{0 . 7 2}(86 \%) & 1.99(82 \%)\end{array}$

* Figures are the means of duplicate estimations which deviated from the mean by less than $5 \%$ except in one case in which the deviation was $9 \%$.

$\dagger$ Bracketed numerals are analytical results for the osmotic preparation expressed as a percentage of the corresponding result for the mechanical preparation.

\section{Conclusion}

It is thus evident that membranes isolated from Halobacterium halobium by osmotic lysis in $0.02 \mathrm{M}-\mathrm{MgCl}_{2}$ retained their morphological identity. In an electron microscope they could not be distinguished with certainty, if at all, from membranes isolated by mechanical breakage. There were no major chemical differences but some minor ones possibly reflected very slight structural differences between the two types of preparation. The importance of such slight differences will depend on the purpose for which the isolated membrane is required. The osmotic method is much quicker and more convenient than the mechanical method with which it was compared and is now being used routinely to obtain membrane lipoproteins for chemical and physico-chemical studies. 
Journal of General Microbiology, Vol. 41, No. 2

Plate 1
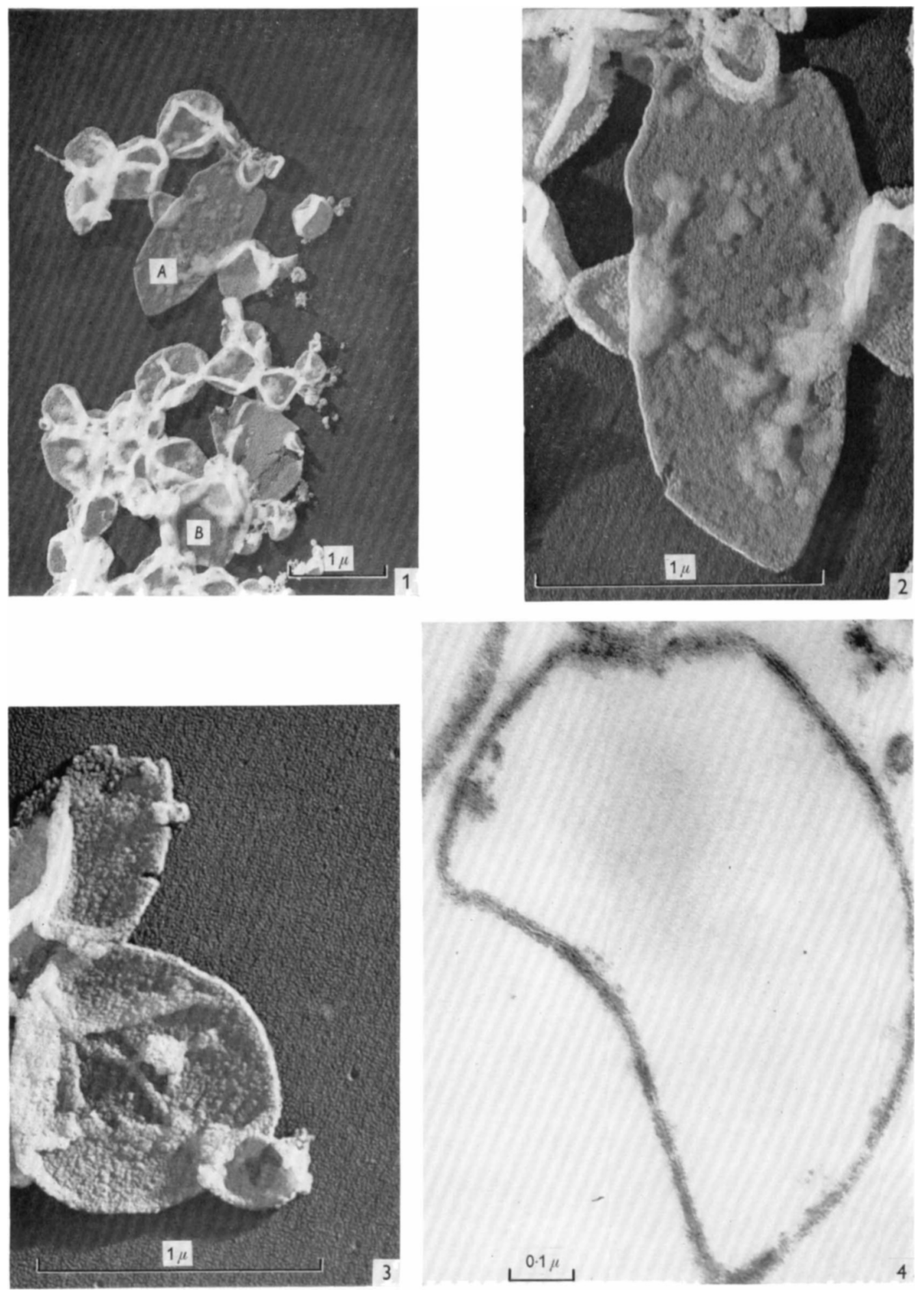

A. D. BROWN, C. D. SHOREY ANI H. P. TURNER

(Facing p. 230) 
Journal of General Microbiology, Vol. 41, No. 2

Plate 2
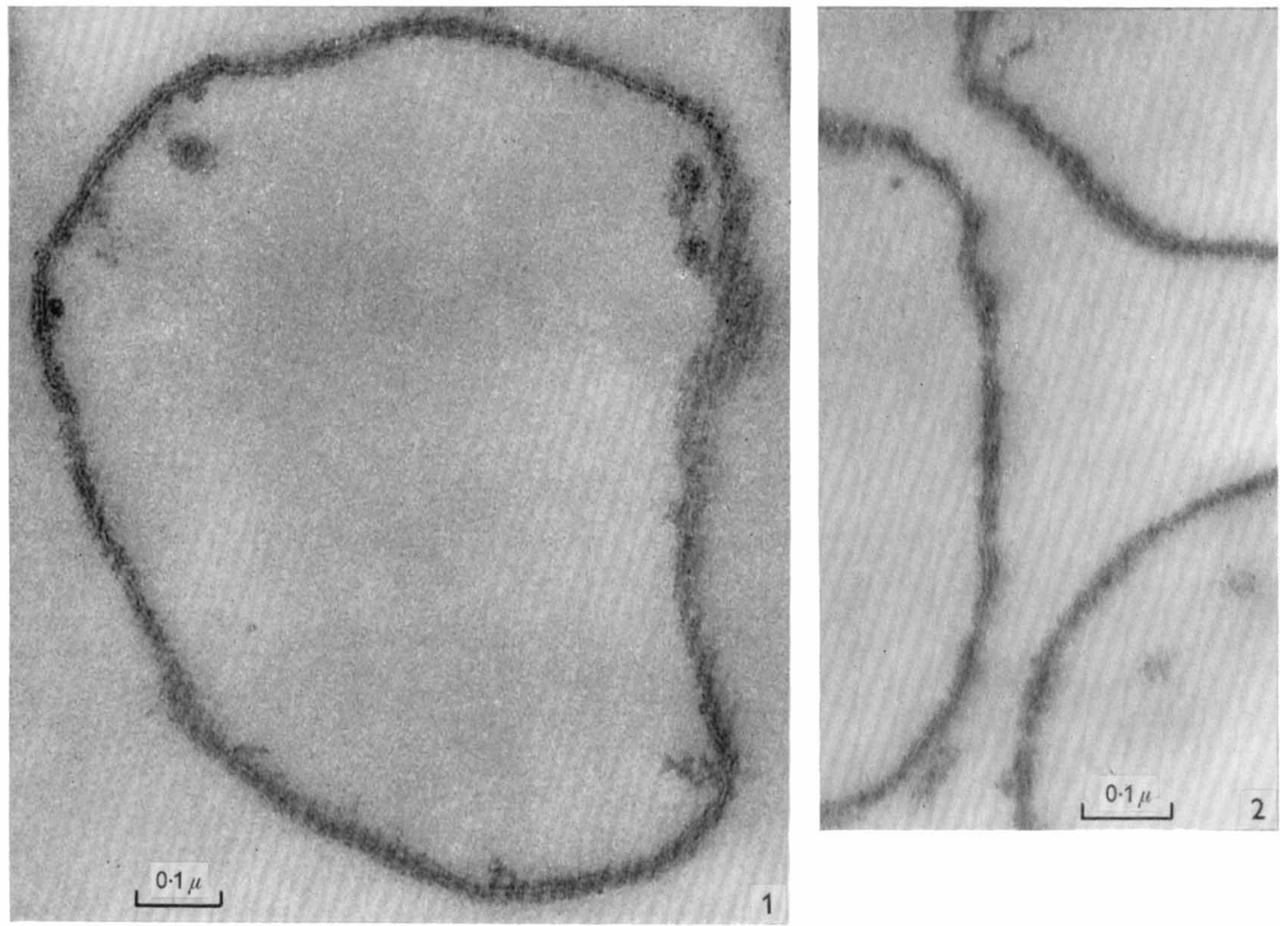

A. D. BROWN, C. D. SHOREY AND H. P. 'TURNER 


\section{REFERENCES}

Brown, A. D. (1961). The peripheral structures of gram-negative bacteria. I. Cell wall protein and the action of a lytic enzyme system of a marine pseudomonad. Biochim. biophys. Acta, 48, 352.

Brown, A. D. (1964). Aspects of bacterial response to the ionic environment. Bact. Rev. 28, 296.

Brown, A. D. (1965). Hydrogen ion titrations of intact and dissolved lipoprotein membranes. J. mol. Biol. 12, 491.

Brown, A. D. \& Shoney, C. D. (1963). The cell envelopes of two extremely halophilic bacteria. J. Cell Biol. 18, 681.

Dische, Z. (1955). New color reagents for determination of sugars in polysaccharides. Meth. biochem. Analysis, 2, 313.

Fiske, C. H. \& Subbarow, Y. (1925). Colorimetric determination of phosphorus. J. biol. Chem. 66, 375.

Houwink, A. L. (1956). Flagella, gas vacuoles and cell-wall structure in Halobacterium halobium; an electron microscope study. J. gen. Microbiol. 15, 146.

Kushner, D. J., Bayley, S. T., Boring, J., Kates, M. \& Gibbons, N. E. (1964). Morphological and chemical properties of cell envelopes of the extreme halophile, Halobacterium cutirubrum. Can. J. Microbiol. 10, 483.

Lowry, O. H., Rosenbrough, N. J., Farr, A. L. \& Randall, R. J. (1951). Protein measurement with the Folin phenol reagent. J. biol. Chem. 193, 265.

Ponder, E. (1961). The cell membrane and its properties. The Cell, 2, 1. Ed. by J. Brachet \& A. E. Mirsky. New York: Academic Press Inc.

Rondle, C. J. M. \& Morgan, W. T. J. (1955). The determination of glucosamine and galactosamine. Biochem. J. 61, 586.

Sehgal, S. N. \& Gibbons, N. E. (1960). Effect of some metal ions on the growth of Halobacterium cutirubrum. Can. J. Microbiol. 6, 165.

\section{EXPLANATION OF PLATES}

\section{Plate 1}

Fig. 1. Membranes isolated by mechanical disintegration of the cells. The surface pattern of this organism has been preserved in one membrane $(A)$ and partly in another $(B) . \times 15,000$.

Fig. 2. The membrane $(A)$ from Fig. 1 shown at higher magnification. This pattern, which has been observed on whole cells and unfixed membranes deposited from suspension in salt solution, has not previously been obtained in fixed membranes. The identity of the larger lumps is not known but they appear to be caused by material occluded within the cell envelope. $\times 45,000$.

Fig. 3. Membranes isolated by osmotic lysis in the presence of $\mathrm{MgCl}_{2}$. The larger membrane has evidently collapsed lengthwise and shows the hole where the cell burst. Patterned membranes were occasionally seen in lytic preparations but no examples as good as Fig. 2 were obtained. $\times 45,000$.

Fig. 4. Section of a membrane isolated from mechanically ruptured cells. $\times 100,000$.

\section{Prate 2}

Fig. 1. Section of a membrane isolated from osmotically ruptured cells. $\times 100,000$.

Fig. 2. Section of membranes isolated from mechanically ruptured cells. Parts of these membranes resemble compound membranes. This appearance was also noted occasionally in membranes isolated by the osmotic method and has previously been reported (Brown \& Shorey, 1963) in sections of whole organisms. $\times 100,000$. 